\title{
COMPORTAMIENTO HIDRÁULICO DE UN FILTRO DE ARENA CON BRAZOS COLECTORES PARA INSTALACIONES DE RIEGO POR GOTEO
}

Pujol, T. ${ }^{1}$, Puig-Bargués, J. ${ }^{2}$, Arbat, G. ${ }^{2}$ (P), Duran-Ros, M. ${ }^{2}$, Solé-Torres, C ${ }^{2}$, Pujol, J. ${ }^{2}$, Ramírez de Cartagena, F. ${ }^{2}$

${ }^{1}$ Departamento de Ingeniería Mecánica y de la Construcción Industrial, Universidad de Girona. toni.pujol@udg.edu

${ }^{2}$ Departamento de Ingeniería Química, Agraria y Tecnología Agroalimentaria. Universidad de Girona. gerard.arbat@udg.edu

\section{Introducción}

La dinámica de fluidos computacional (CFD) permite estudiar hidrodinámicamente distintos equipos de riego como los filtros.

Objetivo: analizar el comportamiento de un filtro de arena con drenaje de brazos colectores mediante CFD para identificar mejoras de diseño.

\section{Material y métodos}

Experimentos con filtro comercial de $500 \mathrm{~mm}$ de diámetro interno con 10 brazos colectores.

Filtro relleno con arena silícea de $0,48 \mathrm{~mm}$ de diámetro efectivo.

Dos alturas de lecho estudiadas: 200 y $300 \mathrm{~mm}$.

Dos caudales estudiados: 6 y $12 \mathrm{~m}^{3} / \mathrm{h}$.

Determinación experimental del caudal y de la caída de presión en el filtro.

Utilización del código Fluent, con modelo de turbulencia k- $\omega$.

Mallado diferencial por zonas, calibración del modelo y análisis de sensibilidad.

\section{Resultados y discusión}

Filtro original [A]: distribución desigual del flujo por brazo.

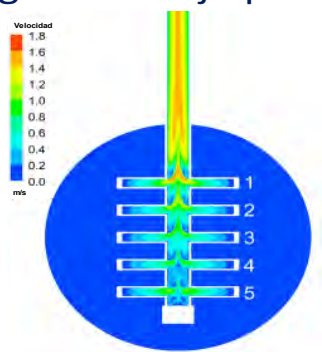

Mejora en la proporción del caudal por brazo
2 diseños alternativos: [B] brazos con igual área superficial y [C] brazos centrales más largos.
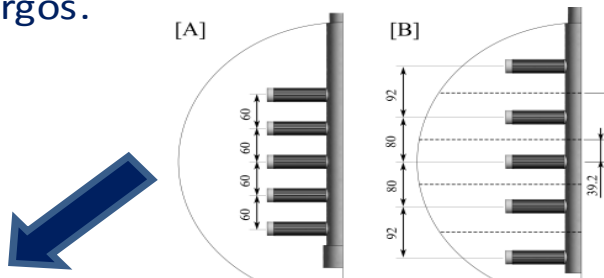

$[\mathrm{C}]$

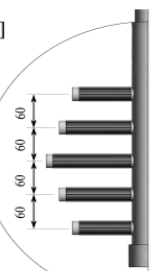

dimensiones en $\mathrm{mm}$

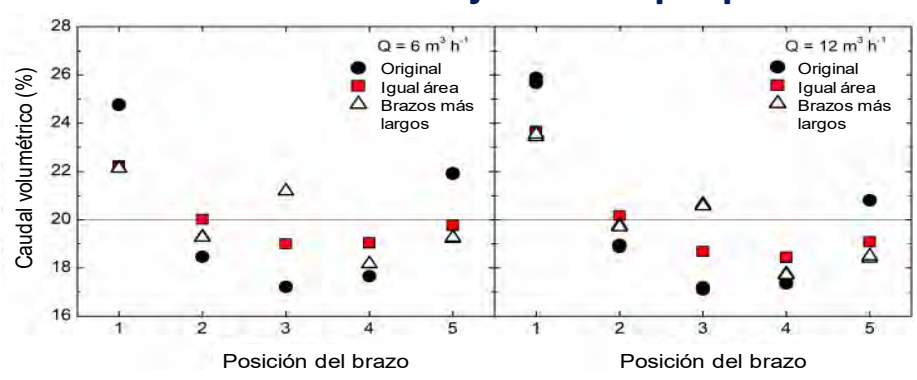

Caudal más uniformemente distribuido con el diseño [B] para los 2 caudales estudiados.

Los nuevos diseños consiguen, además, una reducción de caída depresión del 4,3-5,8\% [B] y del $3,8-5,2 \%[C]$.

\section{Conclusiones}

El diseño actual presenta diferencias de caudal del 44-51\% entre brazos colectores.

Distribuyendo los brazos para que sirvan una misma área superficial se consiguen reducir estas diferencias al 17-28\% en función del caudal. 